\title{
Surgical Treatment of Rectal Prolaps in 83 Year Old Patient. A Case Report.
}

\author{
Nuhi Arslani', Basri Lenjani ${ }^{2}$
}

https://doi.org/10.32391/ajtes.v3i2.58

\section{Abstract}

Background: Prolapse of the rectum is an uncommon problem. It is defined as a protrusion of the rectum through the anus and can cause disability. There is no concensus in literature which surgical approach is the most appropriate. The aim of our case report is to share our experiance and results of the Altemeier procedure.

Case report: 83 years old female patient was admited to the department for general and abdominal surgery. She was diagnosed with rectal prolapse, which could not be reponated. She felt pain and was incontinent.

Results: We decided that optimal treatment for the patient was operation. Altemeier approach was performed. In our opinion, we achieved a favorable outcome.

Conclusion: As stated above there is no clear concensus on which treatment is the most appropriate for rectal prolaps. In our case after careful consideration, we decided that the Altemeier approach was the best solution for the patient.

Keywords: rectal prolapse, Altemeier approach, surgical treatment.

*Corresponding author: Nuhi Arslani

$=\bowtie E$-mail: arslani.nuhi@gmail.com

1Department of Abdominal and General Surgery, University Medical Center Maribor, Maribor, Slovenia.

2Department of Emergency Center, University Medical Center Prishtina, Kosovo. 


\section{Full Text}

\section{Introduction}

Rectal prolapse is protrusion of the rectum through the anus (1). Three different clinical entities are often combined under the umbrella term rectal prolapse: Full-thickness rectal prolapse, mucosal prolapse, internal prolapse (internal intussusception) (2).

The incidence of rectal prolapse has been estimated to be approximately 2.5 per 100,000 inhabitants with a clear predominance among elderly women (3). Female/male ratio is around 10/1 (4).

The etiology is multifactorial and includes weakness of the pelvic floor, chronic constipation, multiple pregnancies, previous pelvic surgery and a deep pouch of Douglas (5)

Full-thickness prolapse of the rectum causes significant discomfort because of the sensation of the prolapse itself, the mucus that it secretes, and because it tends to stretch the anal sphincters and cause incontinence.(6)

Rectal prolapse is a disease, which is an important cause of social and functional problems and has a continuing debate about the ideal surgical treatment (7). The aim of treatment is to control the prolapse, restore continence, and prevent constipation or impaired evacuation (8).

There are different studies suggesting different kinds of treatment. In our case report, we will cite only some of them.

In the article from Eung Jin Shini, it is said that: In elderly and high-risk patients, perineal approaches, such as Delorme's operation and Altemeier's operation, have been preferred, although the incidence of recurrence and the rate of persistent incontinence seem to be high when compared with transabdominal procedures. From the late twentieth century, the laparoscopic procedure has been applied to the treatment of rectal prolapse.(8)

From monitoring the trends in surgical management and outcomes from the American College of Surgeons National Surgical Quality Improvement Program database Authors reported that: Open rectopexy, laparoscopic rectopexy and perineal rectosigmoidectomy. All 3 surgical approaches carry low morbidity among the sick and elderly. In the USA Perineal rectosigmoidectomy remains the predominant approach. (9)

One study which reviewed articles on PUBMED reported that: Perineal procedures are preferable for patients who are not fit for abdominal procedures, such as elderly frail patients with significant comorbidities. The decision between perineal rectosigmoidectomy and Delorme procedures will depend on the surgeon's preference, although the perineal rectosigmoidectomy has better outcomes (10)

And study which was published in 2019 and included 43 female patients which were operated on with Altemeier's procedure reported that: the patients had low complications rate and no mortality. The procedure improved evacuation in constipated patients while it didn't improve fecal and urinary continence. Recurrence of prolapse was $40 \%$ at four years. (5)

\section{Case report}

The 83 year old female patietn was hospitalized for rectal prolapse.

Patient mentions she feels pain in the area of the anus and also reports she has troubles with controling defecation but reports no urinary or gynecological problems. We performed rectal examination: there was a prolapse of the rectum during palpation the patient complained she felt pain, consequently we did not perform a digito rectal examination.

We explained the diagnosis, which was rectal prolaps, the possibility of optimal 
treatment with regard to her condition which is transanal excision, and the possibility that in the event that the state of the disease we will detect during operation will require an additional operation. We explained to her the most common complications and the possibility of unintended complications, which is a rare occurance.

Also, the patient was acquainted with possible additional treatments (abdominal cavity, chest cavity puncture, central channel settings ...), which will be performed in the event her condition will require it. In this regard, she also received basic explanations regarding possible complications (bleeding, unwanted punction of the target organ, pneumatic or chemototoraks.

After that, the patient was admitted to our department for surgical treatment of rectal prolapse, which could not be manually reponated.

After appropriate preoperative preparation, the pation was put in gynecological position, we first performed anemization of the mucous membrane throughout the entire circumference of the prolapse, then we made an incision throughout the entire circumference until we reached mesorectum or mesocolon. In this region, we prepared and ligated vessels with solitary sotures until we reached intestinal circumference. At this level, we performed the excision of the rectosigm at about 8 to $12 \mathrm{~cm}$, after that we created coloanal anastomosis with solitary sotures. The anastomosis was transient. After tha, we concentrated on and achieved hemostasis. In the intestinal lumen, we set spongostan (photo 1-7).

The operation was carried out without major complications.

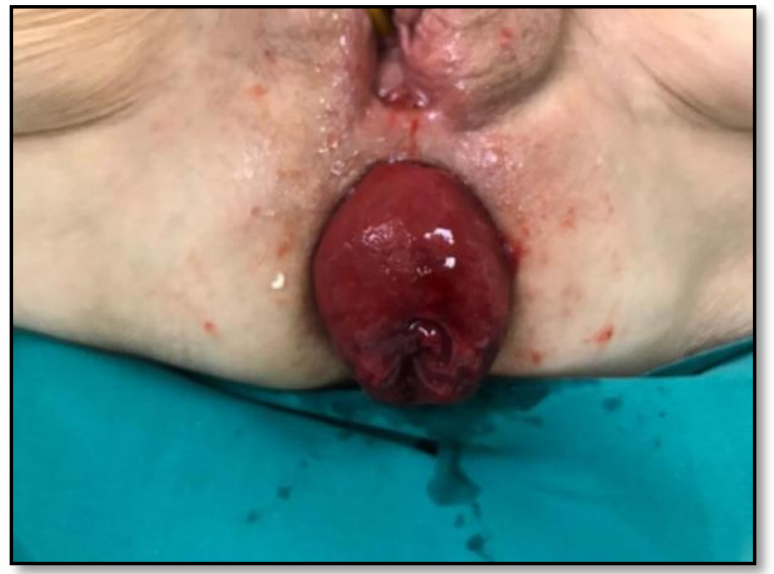

Photo 1: Prolapse of the rectum at the beginning of the operation

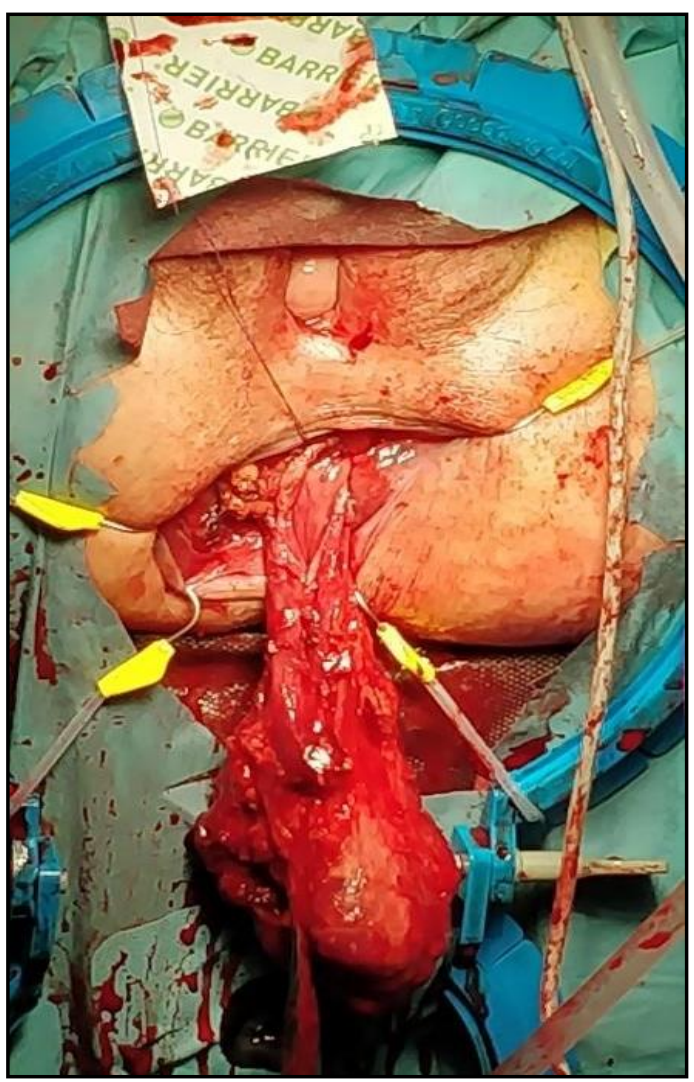

Photo 2 


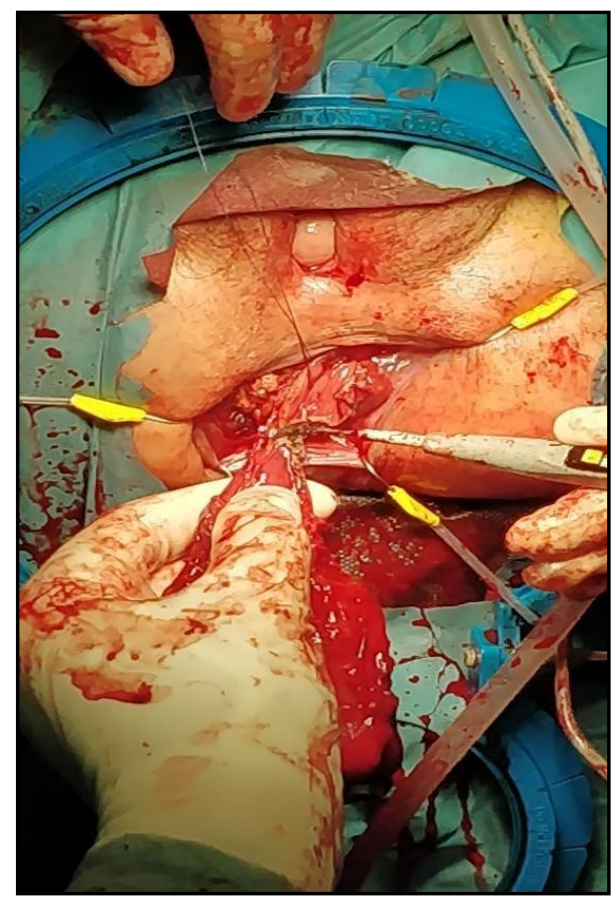

Photo 3

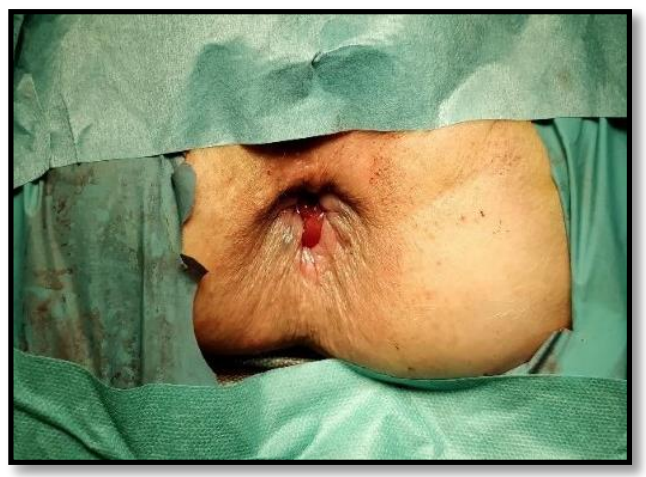

Photo 5: End of surgery

\section{References}

1. Robert S Porter; Justin L Kaplan; Merck \& Co. Rectal prolapse and procidentia. P. 185.Whitehouse Station, N.J. : Merck Sharp \& Dohme Corp., 2011.

2. Gourgiotis S., Baratsis S., Rectal Prolapse. Int. J. Colorectal dis. 2007 Mar. 22 (3), p. 231-43

3. Gallo G, Martellucci J, Pellino G, Ghiselli R, Infantino A, Pucciani F, Trompetto M: Consensus Statement of the Italian Society of Colorectal Surgery (SICCR): management and treatment of complete

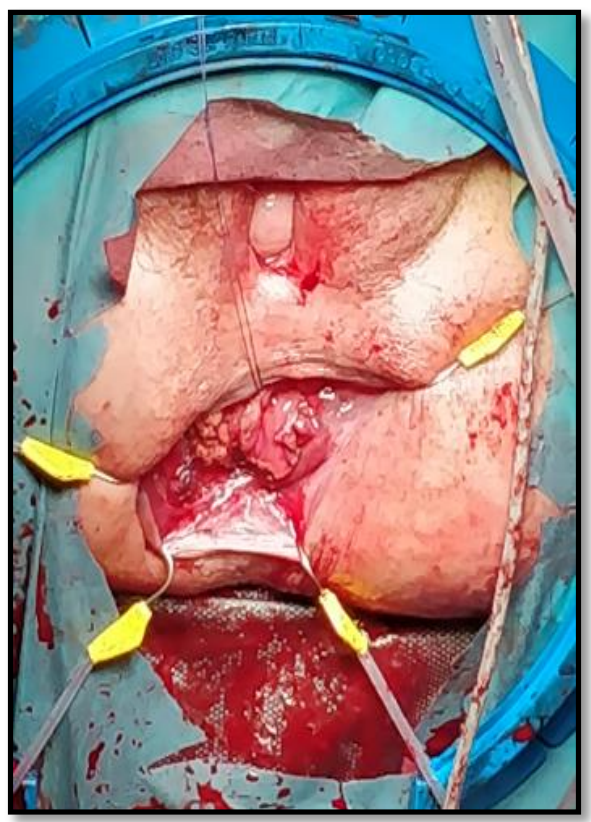

Photo 4 rectal prolapse. Tech Coloproctol. 2018 Dec;22(12):919-931.

4. Kairaluoma MV, Kellokumpu $\mathrm{IH}$. Epidemiologic aspects of complete rectal prolapse. Scand J Surg. 2005;94(3):207-210

5. Mario Trompetto, Roberta Tutino, Alberto Realis Luc, Eugenio Novelli, Gaetano Gallo and Giuseppe Clerico: Altemeier's procedure for complete rectal prolapse; outcome and function in 43 consecutive female patients, BMC Surg. 2019; 19: 1.

6. Eric L. Marderstein, Conor P. Delaney: Surgical management of rectal prolapse. Nature Clinical Practice 
Gastroenterology \& Hepatology volume 4, pages 552-561

7. Kapan Murat, Önder Akın, Polat Serkan, Aliosmanoglu İbrahim, Taskesen Fatih, Arikanoglu Zülfü, Gül Mesut, Taçyıldız İbrahim

8. Shin EJ: Surgical treatment of rectal prolapse. [J Korean Soc Coloproctol] 2011 Feb; Vol. 27 (1), pp. 5-12

9. Daniel VT, Davids JS, Sturrock
PR, Maykel JA, Phatak UR, Alavi: Getting to the bottom of treatment of rectal prolapse in the elderly: Analysis of the National Surgical Quality Improvement Program (NSQIP). Am J Surg. 2019 Feb 12

10. Madiba TE, Baig MK, Wexner SD. Surgical management of rectal prolapse. Arch Surg. 2005 Jan;140(1):6373. 